\title{
A survey study of index food-related allergic reactions and anaphylaxis management
}

\author{
Tammy S. Jacobs ${ }^{1}$, Matthew J. Greenhawt ${ }^{2}$, David Hauswirth ${ }^{3}$, Lynda Mitchell ${ }^{4} \&$ Todd D. Green ${ }^{5}$ \\ ${ }^{1}$ Department of Pediatrics, Children's Hospital of Pittsburgh of UPMC, Pittsburgh, PA, USA; ${ }^{2}$ Division of Allergy \& Immunology, University of \\ Michigan, Ann Arbor, MI, USA; ${ }^{3}$ Division of Pulmonary, Allergy, Critical Care and Sleep Medicine, Department of Internal Medicine, The Ohio \\ State University and Nationwide Children's Hospital, Columbus, OH, USA; ${ }^{4}$ Kids with Food Allergies Foundation, Doylestown, PA, USA; \\ ${ }^{5}$ Division of Pulmonary Medicine, Allergy \& Immunology, Children's Hospital of Pittsburgh of UPMC, Pittsburgh, PA, USA
}

To cite this article: Jacobs TS, Greenhawt MJ, Hauswirth D, Mitchell L, Green TD. A survey study of index food-related allergic reactions and anaphylaxis management. Pediatr Allergy Immunol 2012: 23: 582-589.

\author{
Keywords \\ anaphylaxis; food hypersensitivity; \\ epinephrine; emergency treatment. \\ Correspondence \\ Todd D. Green, Division of Allergy, and \\ Immunology, Children's Hospital of \\ Pittsburgh of UPMC, 4401 Penn Avenue, \\ Suite Floor 3, Pittsburgh, PA 15224, USA. \\ Tel.: 4126927885 \\ Fax: 4126928499 \\ E-mail: todd.green@chp.edu
}

Accepted for publication 17 April 2012

DOI:10.1111/j.1399-3038.2012.01315.x

\begin{abstract}
Background: Initial food-allergic reactions are often poorly recognized and undertreated.

Methods: Parents of food-allergic children were invited to complete an online questionnaire, designed with Kids with Food Allergies Foundation, about their children's first food-allergic reactions resulting in urgent medical evaluation.

Results: Among 1361 reactions, 76\% (95\% CI 74-79\%) were highly likely to represent anaphylaxis based on NIAID/FAAN criteria. Only $34 \%$ (95\% CI $31-37 \%$ ) of these were administered epinephrine. In $56 \%$ of these, epinephrine was administered by emergency departments; $20 \%$ by parents; $9 \%$ by paramedics; $8 \%$ by primary care physicians; and $6 \%$ by urgent care centers. In $26 \%$ of these, epinephrine was given within 15 min of the onset of symptoms; 54\% within $30 \mathrm{~min}$; 82\% within $1 \mathrm{~h}$; and $93 \%$ within $2 \mathrm{~h}$. Factors associated with a decreased likelihood of receiving epinephrine for anaphylaxis included age $<12$ months, milk and egg triggers, and symptoms of abdominal pain and/or diarrhea. Epinephrine was more likely to be given to asthmatic children and children with peanut or tree nut ingestion prior to event. Post-treatment, $42 \%$ of reactions likely to represent anaphylaxis were referred to allergists, $34 \%$ prescribed and/or given epinephrine auto-injectors, $17 \%$ trained to use epinephrine auto-injectors, and $19 \%$ given emergency action plans. Of patients treated with epinephrine, only half $(47 \%)$ were prescribed epinephrine autoinjectors.

Conclusions: Only one-third of initial food-allergic reactions with symptoms of anaphylaxis were recognized and treated with epinephrine. Fewer than half of patients were referred to allergists. There is still a need to increase education and awareness about food-induced anaphylaxis.
\end{abstract}

Anaphylaxis is a severe, rapidly progressive, life-threatening allergic reaction. The diagnosis of anaphylaxis is primarily clinical, and based upon symptoms and signs affecting multiple organ systems (cardiovascular, respiratory, gastrointestinal and/or dermatologic), as well as a detailed history of the acute episode, antecedent exposures, and past medical history. Although debate remains over a clinically useful definition of anaphylaxis, the National Institute of Allergy and Infectious Disease (NIAID) and the Food Allergy and Anaphylaxis Network (FAAN) recently published diagnostic criteria to help clinicians recognize the entire spectrum of manifestations of this potentially fatal disorder (1).

Food allergy affects about $6 \%$ of children $<5 \mathrm{yr}$ of age, and $3-4 \%$ of adults in the United States (2). Food-related reactions include a spectrum of presentations with anaphylaxis being the most severe manifestation. Food allergens are especially concerning because of the potential for certain allergens to cause reaction upon first known ingestion, or to be highly associated with severe reactions. Food allergy is the leading cause (among identified triggers) of anaphylaxis in children and is responsible for half of reported anaphylaxis 
cases presenting to emergency departments (1, 3-12). The incidence of food-induced anaphylaxis has been increasing, particularly within the pediatric population (13-16).

There is limited prior study of the management of anaphylaxis in pediatric populations, especially studies that examine management of anaphylaxis outside the emergency department setting. In this survey study, we examined the management of food-allergic reactions and anaphylaxis in children that caused them to be urgently evaluated by medical professionals for the first time, before those children and their parents were familiar with the manifestation and treatment of those reactions. We hypothesized that food-related anaphylaxis is under-recognized and under-managed in children with initial severe reactions.

\section{Methods}

\section{Study design}

We developed an internet-based, parental survey study in conjunction with Kids with Food Allergies Foundation to examine the management of food-related anaphylaxis in children. Kids with Food Allergies Foundation is a national non-profit food allergy support organization for families raising children with food allergies. Parents of food-allergic children were recruited from website announcements, social networking posts and targeted membership emails to complete a brief (40 questions, $20 \mathrm{~min}$ ) online questionnaire regarding food-related allergic reactions in their children that necessitated urgent medical evaluation for the first time. The survey collected responses between July 28, 2010 and January 13, 2011.

Only survey responses of food-related allergic reactions of children under the age of $18 \mathrm{yr}$ that required urgent medical attention for the first time were included. Only respondents who fully completed surveys were included. All information collected was de-identified. The protocol for this study was approved by the University of Pittsburgh Institutional Review Board.

\section{Measures}

Survey questions included demographics, past medical history, home medications, family history of allergies, probable food allergen exposure, time of onset of symptoms, symptoms, medical providers, epinephrine treatment, treatment provided other than epinephrine, admission outcomes, and discharge instructions concerning the first food-allergic reaction that prompted evaluation and care by a medical professional. In addition to symptoms, participants were asked about physical examination findings that they remember being told by medical staff.

\section{Statistical analysis}

Data were analyzed using StataSE 9.2 (College Station, TX, USA). Anaphylaxis was defined using the National Institute of Allergy and Infectious Disease (NIAID)/Food Allergy and
Anaphylaxis Network (FAAN) criteria (1). Specifically, anaphylaxis is highly likely if there is an acute onset of an illness (minutes to several hours) with involvement of the skin/ mucosal tissue and at least one of either respiratory compromise or reduced blood pressure. Alternatively, anaphylaxis is highly likely if there are two or more of the following that occur rapidly after exposure to a likely allergen (minutes to several hours): involvement of the skin-mucosal tissue, respiratory compromise, reduced blood pressure or associated symptoms, and persistent gastrointestinal symptoms. The third criterion (low blood pressure after exposure to known allergen) is not applicable in this study because these were index reaction, not food allergen. Based on parental reports of presenting symptoms of these reactions, we identified a subset of survey respondents with food-related allergic reactions as highly likely for anaphylaxis.

Descriptive analyses were performed using mean estimations, medians, and binomial proportion estimations. For binary outcome and exposure variables, odds ratios (OR) were calculated using binary logistic regression models.

\section{Results}

\section{Baseline demographic characteristics and past medical history}

The survey collected 1700 responses. After inclusion and exclusion criteria were applied, 1361 survey responses qualified for analysis. Nearly all (except 5) reported index reactions occurred between 1990 and 2010. Using NIAID/FAAN anaphylaxis criteria, we identified a subset of 1044 responses of $1361 \%$ or $76.7 \%(95 \%$ CI $74.5-79.0 \%)$ as highly likely for anaphylaxis (Table 1).

Mean age at the time of the index reactions was 16 months. Just under half $(43.8 \%)$ of the patients were under $1 \mathrm{yr}$ of age. Approximately one-third (35.9\%) of the patients were female. With respect to comorbidities, asthma was present in $18.4 \%$ of the patients, including $20.8 \%$ of those presenting with symptoms highly likely for anaphylaxis, and $10.4 \%$ of those without such symptoms ( $p<0.001$ ). Allergic rhinitis was present in $16.4 \%$ of the patients; $18.0 \%$ of those presenting with symptoms likely for anaphylaxis, and $11.0 \%$ of those without such symptoms $(\mathrm{p}=0.003)$. Atopic dermatitis was present in over half of the patients for both groups. Earlier in the day prior to the allergic events, $2.3 \%$ of the patients had taken asthma rescue medications. Significantly, more patients with likely anaphylaxis were on asthma controller medications (4.9\%), compared with those without likely anaphylaxis $(0.6 \%)(\mathrm{p}<0.001)$. Less than one-tenth of the patients $(8.0 \%)$ had taken antihistamines prior to the index reactions, including $9.1 \%$ of those with likely anaphylaxis, and $4.4 \%$ of those without anaphylaxis (Table 1).

\section{Index food-allergic reaction characteristics}

Approximately one-third $(29.5 \%)$ of food-allergic reactions that required medical attention for the first time reported 
Table 1 Demographic characteristics and medical history of patients with food-related allergic reactions with and without anaphylaxis ( $n=1361)$

\begin{tabular}{|c|c|c|c|c|}
\hline Demographics/medical history & $\begin{array}{l}\text { Anaphylaxis } \\
\mathrm{n}(\%)\end{array}$ & $\begin{array}{l}\text { No anaphylaxis } \\
\text { n (\%) }\end{array}$ & $\begin{array}{l}\text { Total } \\
\text { n (\%) }\end{array}$ & $p^{*}$ \\
\hline Total, n (\%) & $1044(76.7)$ & $317(23.3)$ & $1361(100.0)$ & \\
\hline \multicolumn{5}{|l|}{ Demographics } \\
\hline Mean age (months) & 18 & 12 & 16 & $<0.001$ \\
\hline Age $<1$ yr & $442(42.3)$ & 154 (48.6) & $596(43.8)$ & 0.050 \\
\hline Gender (female) & $378(36.2)$ & $110(34.7)$ & 488 (35.9) & 0.624 \\
\hline \multicolumn{5}{|l|}{ Medical history } \\
\hline Asthma & $217(20.8)$ & $33(10.4)$ & $250(18.4)$ & $<0.001$ \\
\hline Allergic rhinitis & $188(18.0)$ & $35(11.0)$ & $223(16.4)$ & 0.003 \\
\hline Atopic dermatitis & $596(57.1)$ & $195(61.5)$ & $791(58.1)$ & 0.162 \\
\hline Eosinophilic esophagitis & $33(3.2)$ & $0(0.0)$ & $33(2.4)$ & 0.001 \\
\hline Hymenoptera allergy & $6(0.6)$ & $0(0.0)$ & $6(0.4)$ & 0.176 \\
\hline Gastroesophageal reflux & $150(14.4)$ & $26(8.2)$ & $176(12.9)$ & 0.004 \\
\hline \multicolumn{5}{|l|}{ Medications taken prior to event } \\
\hline Asthma rescue meds & $28(2.7)$ & $3(1.0)$ & $31(2.3)$ & 0.070 \\
\hline Asthma controller meds & $51(4.9)$ & $2(0.6)$ & 53 (3.9) & 0.001 \\
\hline Antihistamines & $95(9.1)$ & $14(4.4)$ & $109(8.0)$ & 0.007 \\
\hline Gastroesophageal reflux meds & $71(6.8)$ & $16(5.1)$ & $87(6.4)$ & 0.264 \\
\hline
\end{tabular}

*The p-value for a chi-square test.

peanut as the food trigger; $27.9 \%$ in those with likely anaphylaxis, and $34.7 \%$ in those without likely anaphylaxis $(p=0.020)$. Significantly, more patients with likely anaphylaxis reported milk as the inciting food $(35.5 \%)$, compared with those without anaphylaxis $(28.4 \%)(p=0.019)$. Eleven percent of the patients $(11.8 \%)$ reported tree nut ingestion prior to the index reaction; $14.2 \%$ egg ingestion, $5.1 \%$ wheat ingestion, $3.8 \%$ soy ingestion, $1.3 \%$ fish ingestion, and $0.5 \%$ shellfish ingestion (Table 2).

The median time after food ingestion to reported onset of symptoms for the index reactions was within $30 \mathrm{~min}$. About half $(48.4 \%)$ of the index reactions occurred while the child was eating the inciting food, $79.1 \%$ of the reactions occurred within $30 \mathrm{~min}$ after food ingestion, $86.0 \%$ within $1 \mathrm{~h}, 93.9 \%$ within $2 \mathrm{~h}, 96.6 \%$ within $4 \mathrm{~h}$, and $97.7 \%$ within $6 \mathrm{~h}$. There

Table 2 Foods ingested that resulted in food-related allergic reactions with and without anaphylaxis $(n=1361)$

\begin{tabular}{lcccc}
\hline Foods ingested & $\begin{array}{l}\text { Anaphylaxis } \\
\mathrm{n}(\%)\end{array}$ & $\begin{array}{l}\text { No anaphylaxis } \\
\mathrm{n}(\%)\end{array}$ & $\begin{array}{l}\text { Total } \\
\mathrm{n}(\%)\end{array}$ & $\mathrm{p}^{*}$ \\
\hline Total, $\mathrm{n}(\%)$ & $1044(76.7)$ & $317(23.3)$ & $1361(100.0)$ & \\
Peanut & $291(27.9)$ & $110(34.7)$ & $401(29.5)$ & 0.020 \\
Tree nut & $133(12.7)$ & $28(8.8)$ & $161(11.8)$ & 0.059 \\
Milk & $371(35.5)$ & $90(28.4)$ & $461(33.9)$ & 0.019 \\
Egg & $144(13.8)$ & $49(15.5)$ & $193(14.2)$ & 0.457 \\
Wheat & $51(4.9)$ & $19(6.0)$ & $70(5.1)$ & 0.434 \\
Soy & $38(3.6)$ & $13(4.1)$ & $51(3.8)$ & 0.705 \\
Fish & $15(1.4)$ & $2(0.6)$ & $17(1.3)$ & 0.258 \\
Shellfish & $7(0.7)$ & $0(0.0)$ & $7(0.5)$ & 0.144 \\
Other & $95(9.1)$ & $43(13.6)$ & $138(10.1)$ & 0.021 \\
Unknown & $71(6.8)$ & $20(6.3)$ & $91(6.7)$ & 0.759 \\
\hline
\end{tabular}

*The p-value for a chi-square test. were no significant differences between the group with highly likely anaphylaxis and the group without such symptoms.

Almost all of the patients $(93.5 \%)$ reported developing skin and/or mucosal symptoms. A small percentage $(3.5 \%)$ of likely anaphylaxis case did not report skin and/or mucosal symptoms. Over half of the patients $(61.8 \%)$ had respiratory symptoms. This included $79.2 \%$ of those with likely anaphylaxis, compared with only $4.4 \%$ of those without likely anaphylaxis. One-quarter of the patients $(25.4 \%)$ reported cardiovascular symptoms, including $32.1 \%$ of those with likely anaphylaxis, compared with only $3.2 \%$ of those without anaphylaxis. Gastrointestinal symptoms were present in about half of the patients $(52.9 \%)$, including $66.0 \%$ of those with likely anaphylaxis, and in $9.8 \%$ of those without anaphylaxis. Biphasic symptoms were present in under one-fifth of patients $(17.2 \%)$.

\section{Epinephrine administration and anaphylaxis management}

Epinephrine administration information was available in 1300 of 1361 survey responses because of missing data or respondent uncertainty. Of those, $988 / 1300$ or $76.0 \%(95 \%$ CI $74.4-79.0 \%$ ) of index reactions met NIAID/FAAN criteria as highly likely for anaphylaxis. Only $339 / 988$ or $34.3 \%$ (95\% CI 31.3-37.3\%) of patients with food-induced anaphylaxis reported they received epinephrine, compared with $7.7 \%$ of patients without anaphylaxis (Fig. 1).

Of the index reactions judged to have anaphylaxis and administered epinephrine, it was administered by emergency departments in $56.1 \%(190 / 339)$, pre-hospital by parents in $20.1 \%(68 / 339)$, by paramedics in $9.4 \%(32 / 339)$, by primary care physicians in $8.3 \%(28 / 339)$, and by urgent care centers in $6.2 \%(21 / 339)$ of cases. 


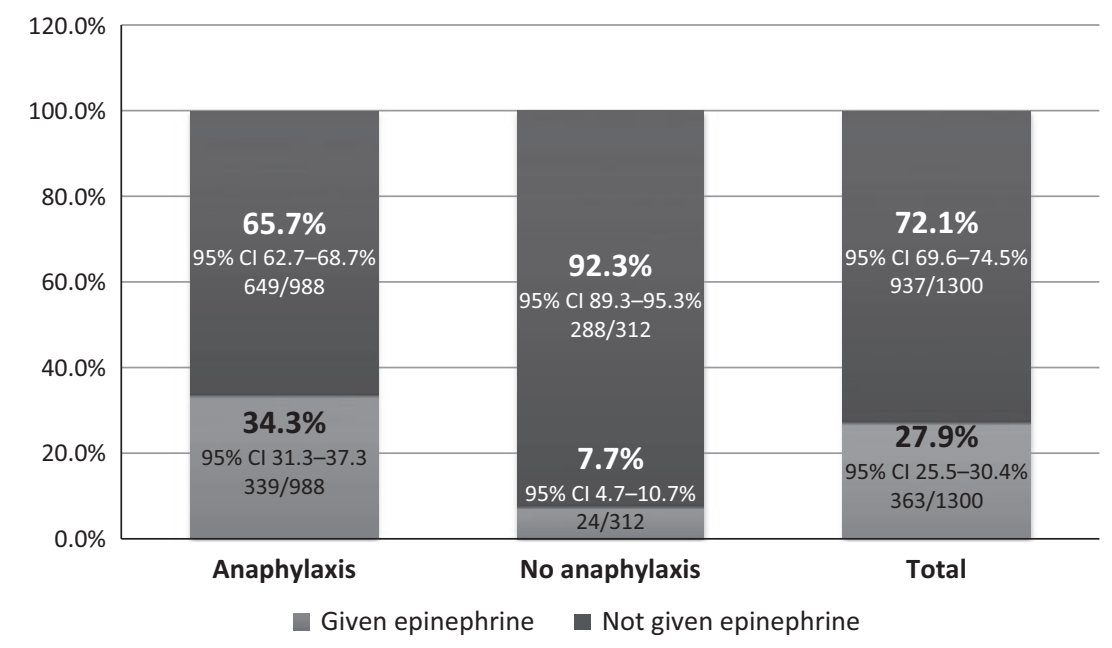

Figure 1 Epinephrine given to patients with food-related allergic reactions with and without anaphylaxis $(\mathrm{n}=1300)$.

The median time between development of symptoms and reported epinephrine administration by all providers combined in likely anaphylaxis cases was between 15 and $30 \mathrm{~min}$. In the likely anaphylaxis cases, median reported response time for epinephrine administration was within $15 \mathrm{~min}$ by parents, 15-30 min for paramedics and primary care center, and 30-60 min for urgent care centers to emergency departments. Epinephrine was administered within $15 \mathrm{~min}$ of the onset of symptoms in $26.3 \%$ of likely anaphylaxis cases, $53.7 \%$ within $30 \mathrm{~min}, 81.7 \%$ within $1 \mathrm{~h}$, and $92.9 \%$ within 2 h (Table 3).

Factors associated with a decreased likelihood of receiving epinephrine in anaphylaxis included being $<12$ months of age (OR 2.26, 95\% CI 1.71-2.99), reported milk (OR 1.48, $95 \%$ CI 1.11-1.96) and egg (OR 1.52, 95\% CI 1.01-1.27)

Table 3 Timing of epinephrine given to patients of food-related allergic reactions with and without anaphylaxis $(n=363)$

\begin{tabular}{|c|c|c|}
\hline Timing & $\begin{array}{l}\text { Anaphylaxis } \\
\text { n (cumulative \%) }\end{array}$ & $\begin{array}{l}\text { No anaphylaxis } \\
\text { n (cumulative \%) }\end{array}$ \\
\hline Total, n (\%) & $339(93.4)$ & $24(6.6)$ \\
\hline \multicolumn{3}{|l|}{ Median time } \\
\hline All providers & $15-30 \mathrm{~min}$ & 15-60 min \\
\hline Parents & Within $15 \mathrm{~min}$ & Within $15 \mathrm{~min}$ \\
\hline Paramedics & $15-30 \mathrm{~min}$ & Within $15 \mathrm{~min}$ \\
\hline Primary care center & $15-30 \mathrm{~min}$ & Within 15 min \\
\hline Urgent care center & $30-60 \mathrm{~min}$ & No observations \\
\hline $\begin{array}{l}\text { Emergency } \\
\text { department }\end{array}$ & $30-60 \mathrm{~min}$ & $30-60 \mathrm{~min}$ \\
\hline Within $15 \mathrm{~min}$ & 89 (26.3) & $7(29.2)$ \\
\hline Within $30 \mathrm{~min}$ & $93(53.7)$ & $5(50.0)$ \\
\hline Within $1 \mathrm{~h}$ & $95(81.7)$ & $4(66.7)$ \\
\hline Within $2 \mathrm{~h}$ & 38 (92.9) & $5(87.5)$ \\
\hline Within $4 \mathrm{~h}$ & 17 (97.9) & $2(95.8)$ \\
\hline$>4 \mathrm{~h}$ & $7(100.0)$ & $1(100.0)$ \\
\hline
\end{tabular}

triggers, reporting at least one gastrointestinal symptom (OR $1.35,95 \%$ CI 1.03-1.78), abdominal pain (OR 1.56, 95\% CI 1.08-2.24), and diarrhea (OR 1.64, 95\% CI 1.14-2.36). Factors associated with an increased likelihood of receiving epinephrine for anaphylaxis included being a known asthmatic (OR 1.39, 95\% CI 1.01-1.90), reported peanut (OR 1.45, $95 \%$ CI 1.09-1.94), and tree nut (OR 1.50, 95\% CI 1.02 $2.18)$ triggers, as well as most skin, mucosal, respiratory and cardiovascular symptoms and signs. Reported wheat, soy, fish or shellfish triggers did not increase or decrease likelihood of receiving epinephrine for anaphylaxis. The year in which the reported index reaction occurred also did not affect the likelihood of receiving epinephrine for anaphylaxis (Table 4).

Antihistamines were used to treat most (93.1\%) index reactions, including $92.4 \%$ of those with likely anaphylaxis, and $95.3 \%$ of those without likely anaphylaxis. Steroids were additionally used in $81.6 \%$ of those reactions, including $80.8 \%$ of those reactions with likely anaphylaxis, and $84.5 \%$ of those without anaphylaxis. Intravenous fluids, respiratory treatments and/or oxygen were administered in about twothirds of reactions. Less than $1 \%$ of reactions required intubation. About $10 \%$ of reactions required admission to the hospital, significantly more for those with anaphylaxis $(12.0 \%)$ than those without anaphylaxis $(3.2 \%)(p<0.001)$. Close to $3 \%$ of patients with likely anaphylaxis were admitted to the intensive care unit, though none in those without anaphylaxis (Fig. 2).

\section{Discharge care and instructions for food allergy and anaphy-} laxis

Post-treatment in the subset of index reactions with anaphylaxis, $33.0 \%$ were prescribed epinephrine auto-injectors, $16.7 \%$ were trained to use epinephrine auto-injectors, and $7.5 \%$ were given epinephrine auto-injectors. Approximately $42.3 \%$ of anaphylaxis cases were referred to allergists. Less 
Table 4 Variables associated with under-treatment (no epinephrine) and variables associated with epinephrine treatment in cases of food-related anaphylaxis ( $n=988$ )

\begin{tabular}{|c|c|}
\hline & OR $(95 \% \mathrm{Cl})^{*}$ \\
\hline \multicolumn{2}{|c|}{ Variables associated with under-treatment (no epinephrine) } \\
\hline \multicolumn{2}{|c|}{ Demographic } \\
\hline Age $<12$ months & $2.26(1.71-2.99)$ \\
\hline \multicolumn{2}{|l|}{ Inciting food (prior to event) } \\
\hline Milk & $1.48(1.11-1.96)$ \\
\hline Egg & $1.52(1.01-2.27)$ \\
\hline \multicolumn{2}{|l|}{ Symptoms } \\
\hline Having at least one gastrointestinal & $1.35(1.03-1.78)$ \\
\hline \multicolumn{2}{|l|}{ symptom } \\
\hline Abdominal pain & $1.56(1.08-2.24)$ \\
\hline Diarrhea & $1.64(1.14-2.36)$ \\
\hline \multirow{2}{*}{\multicolumn{2}{|c|}{$\begin{array}{l}\text { Variables associated with epinephrine treatment } \\
\text { Past medical history }\end{array}$}} \\
\hline & \\
\hline Asthma & $1.39(1.01-1.90)$ \\
\hline \multicolumn{2}{|l|}{ Inciting food (ingested prior to event) } \\
\hline Peanut & $1.45(1.09-1.94)$ \\
\hline Treenut & $1.50(1.02-2.18)$ \\
\hline Transport by ambulance & $4.28(3.07-5.96)$ \\
\hline \multicolumn{2}{|l|}{ Symptoms } \\
\hline \multicolumn{2}{|l|}{ Skin symptoms } \\
\hline Facial erythema & $1.49(1.14-1.94)$ \\
\hline Facial edema & $2.07(1.58-2.71)$ \\
\hline Generalized hives & $1.48(1.13-1.93)$ \\
\hline Generalized flushing & $1.37(1.05-1.78)$ \\
\hline Swollen extremities & $2.10(1.41-3.11)$ \\
\hline Generalized pruritus & $1.35(1.02-1.78)$ \\
\hline \multicolumn{2}{|l|}{ Mucosal symptoms } \\
\hline Having at least one mucosal symptom & $2.45(1.70-3.54)$ \\
\hline Angioedema & $3.27(2.49-4.30)$ \\
\hline Eye symptoms & $1.38(1.06-1.80)$ \\
\hline Dysphagia & $2.93(2.17-3.96)$ \\
\hline Choking sensation & $2.55(1.87-3.47)$ \\
\hline \multicolumn{2}{|l|}{ Respiratory symptoms } \\
\hline Having at least one respiratory symptom & $2.54(1.75-3.68)$ \\
\hline Dysphonia & $2.17(1.57-3.00)$ \\
\hline Cough & $1.84(1.41-2.40)$ \\
\hline Dyspnea & $2.79(2.08-3.74)$ \\
\hline Chest tightness & $2.74(1.79-4.20)$ \\
\hline Noisy breathing & $2.18(1.67-2.85)$ \\
\hline Cyanosis & $2.38(1.55-3.63)$ \\
\hline Wheezing & $2.35(1.77-3.11)$ \\
\hline \multicolumn{2}{|l|}{ Cardiovascular symptoms } \\
\hline $\begin{array}{l}\text { Having at least one cardiovascular } \\
\text { symptom }\end{array}$ & $2.35(1.79-3.08)$ \\
\hline Chest pain & $4.40(1.34-14.39$ \\
\hline Dizziness & $1.84(1.12-3.00)$ \\
\hline Syncope & $1.88(1.02-3.47)$ \\
\hline Diaphoresis & $1.62(1.03-2.53)$ \\
\hline Palpitations & $2.39(1.17-4.92)$ \\
\hline Confusion and mental status changes & $2.02(1.26-3.26)$ \\
\hline Hypotension & $2.43(1.59-3.73)$ \\
\hline Tachycardia & $3.86(2.56-5.82)$ \\
\hline
\end{tabular}

*OR was calculated using binary logistic regression. than one-quarter $(19.1 \%)$ were given anaphylaxis emergency medical plans. About one-third of anaphylactic reactions were prescribed steroids $(31.8 \%)$ and antihistamines $(39.7 \%)$. About one-tenth were prescribed bronchodilators (13.0\%). Of patients treated with epinephrine, less than half were prescribed epinephrine auto-injectors (47.1\%) (Table 5).

\section{Discussion}

In this study, we examined the management of anaphylaxis in a group of patients at significant risk for under-diagnosis and treatment - children with first-time reactions that require medical evaluation before food allergies are formally diagnosed. Our results suggest that anaphylaxis is underrecognized and under-treated in patients without a prior food allergy diagnosis. Only one-third of reported likely anaphylaxis cases were administered epinephrine. Post-treatment, only one-third of patients with likely anaphylaxis were prescribed epinephrine auto-injectors, and less than half were referred to allergists. More than half of patients treated with epinephrine were not prescribed epinephrine auto-injectors.

Our findings support prior studies suggesting that foodinduced anaphylaxis is often poorly recognized and undertreated (17-23). Our findings again support a need for more direct education regarding the broad diagnostic criteria of anaphylaxis, given that the presentation can be subtle, lack cutaneous symptoms, and not always be associated with cardiovascular collapse. In a prior study of fatal and near-fatal anaphylaxis cases in children, cutaneous symptoms and signs were less common in food-induced anaphylaxis deaths compared with those who survived (24). Many of the symptoms and signs of anaphylaxis can be non-specific or misleading, such as confusion, presyncope, collapse, or abdominal pain, all of which carry broad differential diagnoses. Anaphylaxis may be mistaken for an asthma exacerbation if signs of cutaneous symptoms are overlooked, and/or if signs of cardiovascular involvement are misattributed to side effects of bronchodilator treatment. Anaphylaxis is likely under-diagnosed for these and a variety of other reasons (7, 19, 25-27). Under-recognition and subsequent under-treatment of foodrelated anaphylaxis may be particularly pronounced in the pediatric population, especially in children presenting with their first episode of anaphylaxis. Previous reports show that a large proportion of anaphylactic reactions had no previous history of anaphylaxis or food allergies $(22,28)$.

Recognition of the variable and atypical presentations of anaphylaxis is critical to providing frontline therapy with intramuscular epinephrine, as well as reducing overreliance on less-effective adjunctive medications as primary therapies, such as antihistamines and glucocorticoids. Timely administration of epinephrine is the only intervention that has been shown to effectively treat the severity of the allergic reactions $(29,30)$. Several case studies have implicated the failure of rapid administration of epinephrine as a consistent finding in anaphylaxis deaths $(24,31-37)$. Prior studies show that the use of epinephrine is not consistent in both children and adults and that physician knowledge of anaphylaxis management guidelines is inadequate $(20-22,28,38)$. Prompt, early 


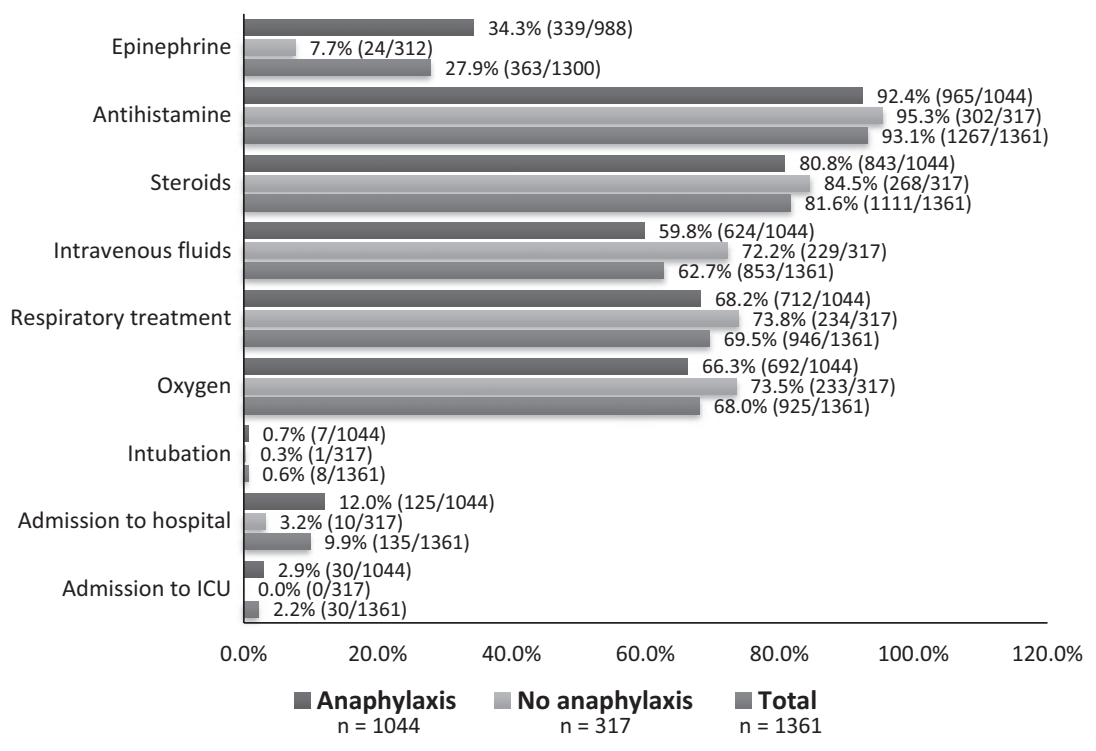

Figure 2 Medications, treatments and interventions provided to patients of food-related allergic reactions with and without anaphylaxis ( $n=1361)$.

Table 5 Discharge care and instructions provided to patients with food-related anaphylaxis and those given epinephrine (treated as anaphylaxis)

\begin{tabular}{|c|c|c|}
\hline Discharge care and instructions & $\begin{array}{l}\text { Anaphylaxis } \\
\mathrm{n}(\%)\end{array}$ & $\begin{array}{l}\text { Given epinephrine } \\
\mathrm{n}(\%)\end{array}$ \\
\hline Total, n (\%) & $988(76.0)$ & $363(27.9)$ \\
\hline $\begin{array}{l}\text { Given anaphylaxis emergency } \\
\text { action plan }\end{array}$ & $199(19.1)$ & $98(27.0)$ \\
\hline Educated about biphasic reactions & $204(19.5)$ & $125(34.4)$ \\
\hline Allergy referral & $442(42.3)$ & $152(41.9)$ \\
\hline $\begin{array}{l}\text { Prescribed epinephrine } \\
\text { auto-injectors }\end{array}$ & $344(33.0)$ & $171(47.1)$ \\
\hline Given epinephrine auto-injectors & 78 (7.5) & $36(9.9)$ \\
\hline $\begin{array}{l}\text { Trained to use epinephrine } \\
\text { auto-injectors }\end{array}$ & $174(16.7)$ & $77(21.2)$ \\
\hline Prescribed steroids & $332(31.8)$ & $185(51.0)$ \\
\hline Prescribed antihistamines & $414(39.7)$ & $152(41.9)$ \\
\hline Prescribed bronchodilators & $136(13.0)$ & $56(15.4)$ \\
\hline
\end{tabular}

administration of epinephrine is a potentially modifiable factor in improving anaphylaxis survival.

In an effort to identify potential areas for educational and therapeutic improvement, we identified risk factors for undertreatment with epinephrine. Milk and egg allergies are more common in infants and young children, and fatal milk allergies affect mostly children $(9,10,24,32,34,39$, 40). However, our study found that infancy, milk and egg triggers, and reported gastrointestinal symptoms were independently associated with anaphylaxis under-recognition and treatment. Factors in our data set associated with an increased likelihood of receiving epinephrine - asthma, and peanut and tree nut allergies - correspond with well-established risk factors for food-induced anaphylaxis and fatality $(6,24,31-36,39$, 41).

There are several limitations of this study. Foremost, this is a self-reported study assessing parental interpretation of a reaction and its associated factors. However, studies of this nature are routinely conducted as it is a practical and useful way to assess food allergy in a large population. Another notable limitation inherent to survey studies is recall bias. We recognize that parents have varying levels of medical knowledge and may not acknowledge certain medications, treatments, or counseling provided especially under exigent circumstances. To limit recall errors, we provided choices for uncertainty. These responses were not included in proportion estimates. With these acknowledged limits, a large proportion of cases were identified as highly likely for food-induced anaphylaxis, using the NIAID/FAAN criteria. Some of this may be explained by participation bias from respondents who had a more severe event that they are less likely to overlook or that may have been their motivation to take such a survey. We have consistently labeled the reaction as 'likely' or 'highly likely' for anaphylaxis, because we did not assess these patients directly, and are relying on parental report of what occurred, to account for biases in using these criteria. However, we highlight that such reports are no different from taking a history in the office of a past event, which one also would not have been able to assess. Additionally, prior less severe reactions may have been self-treated and therefore missed as the initial presentation of food allergy. A separate analysis was performed limiting highly likely anaphylaxis to those reactions that occurred within $1-2 \mathrm{~h}$ (we included all cases in this analysis); the proportion estimates of likely anaphylaxis cases and epinephrine treatment did not significantly change. Because of this selection bias and intrinsic survey study design, we acknowledge that the incidence of 
anaphylaxis in first-time food-induced allergic reactions requiring medical care cannot be gathered from this study.

The parental survey design allowed for study beyond emergency department management (to which retrospective chart review designs were limited), but also included management by other medical professionals often not part of the medical record. It is clear from our study that emergency departments were not the only location where initial anaphylaxis cases presented. About $8 \%$ of epinephrine administration in anaphylaxis occurred in primary care physician offices. Only about half of epinephrine administration in anaphylaxis occurred in the emergency departments. In fact, the median time to reported epinephrine administration was shorter in primary care offices than in emergency departments.

We examined the management of first-time food-related reactions in children without prior diagnoses of food allergies using a parental survey study design and found that anaphylaxis is under-recognized and under-treated. In this study, only one-third of reported likely anaphylaxis cases were administered epinephrine. These findings suggest that the clinical presentation of a patient experiencing anaphylaxis is often poorly recognized and that improved education and awareness is necessary to raise the standard response to anaphylaxis at all provider levels.

\section{References}

1. Sampson HA, Munoz-Furlong A, Campbell RL, et al. Second symposium on the definition and management of anaphylaxis: summary report - Second National Institute of Allergy and Infectious Disease/Food Allergy and Anaphylaxis Network symposium. J Allergy Clin Immunol 2006: 117: 391-7.

2. Sicherer SH, Sampson HA. 9. Food allergy. J Allergy Clin Immunol 2006: 117 (2 Suppl. Mini-Primer): S470-5.

3. Gupta RS, Springston EE, Warrier MR, et al. The prevalence, severity, and distribution of childhood food allergy in the United States. Pediatrics 2011: 128: e9-17.

4. Lieberman P, Nicklas RA, Oppenheimer J, et al. The diagnosis and management of anaphylaxis practice parameter: 2010 update. J Allergy Clin Immunol 2010: 126: 477-80, e1-42.

5. Kemp SF, Lockey RF. Anaphylaxis: a review of causes and mechanisms. J Allergy Clin Immunol 2002: 110: 341-8.

6. Sampson HA, Munoz-Furlong A, Bock SA, et al. Symposium on the definition and management of anaphylaxis: summary report. J Allergy Clin Immunol 2005: 115: 584-91.

7. Simons FE. Anaphylaxis, killer allergy: long-term management in the community. J Allergy Clin Immunol 2006: 117: 367-77.

8. Simons FE, Frew AJ, Ansotegui IJ, et al. Risk assessment in anaphylaxis: current and future approaches. $J$ Allergy Clin Immunol 2007: 120 (1 Suppl.): S2-24.

9. Brown AF, McKinnon D, Chu K. Emergency department anaphylaxis: a review of 142 patients in a single year. J Allergy Clin Immunol 2001: 108: 861-6.

10. Sampson HA. Anaphylaxis and emergency treatment. Pediatrics 2003: 111 (6 Pt 3): 1601-8.

11. Smit DV, Cameron PA, Rainer TH. Anaphylaxis presentations to an emergency department in Hong Kong: incidence and predictors of biphasic reactions. $J$ Emerg Med 2005: 28: 381-8.
12. Wang J, Sampson HA. Food anaphylaxis. Clin Exp Allergy 2007: 37: 651-60.

13. Gupta R, Sheikh A, Strachan DP, Anderson HR. Time trends in allergic disorders in the UK. Thorax 2007: 62: 91-6.

14. Gupta R, Sheikh A, Strachan D, Anderson HR. Increasing hospital admissions for systemic allergic disorders in England: analysis of national admissions data. BMJ 2003: 327: 1142-3.

15. Poulos LM, Waters AM, Correll PK, Loblay RH, Marks GB. Trends in hospitalizations for anaphylaxis, angioedema, and urticaria in Australia, 1993-1994 to 20042005. J Allergy Clin Immunol 2007: 120: 878-84.

16. Rudders SA, Banerji A, Vassallo MF, Clark $\mathrm{S}$, Camargo CA Jr. Trends in pediatric emergency department visits for foodinduced anaphylaxis. J Allergy Clin Immunol 2010: 126: 385-8.

17. Decker WW, Campbell RL, Manivannan $\mathrm{V}$, et al. The etiology and incidence of anaphylaxis in Rochester, Minnesota: a report from the Rochester Epidemiology Project. J Allergy Clin Immunol 2008: 122: 1161-5.

18. Lieberman P, Camargo CA Jr, Bohlke K, et al. Epidemiology of anaphylaxis: findings of the American College of Allergy, Asthma and Immunology Epidemiology of Anaphylaxis Working Group. Ann Allergy Asthma Immunol 2006: 97: 596-602.

19. Lin RY, Anderson AS, Shah SN, Nurruzzaman F. Increasing anaphylaxis hospitalizations in the first 2 decades of life: New York State, 1990-2006. Ann Allergy Asthma Immunol 2008: 101: 387-93.

20. Clark S, Bock SA, Gaeta TJ, Brenner BE, Cydulka RK, Camargo CA. Multicenter study of emergency department visits for food allergies. J Allergy Clin Immunol 2004: 113: 347-52.

21. Clark S, Camargo CA Jr. Emergency management of food allergy: systems perspective. Curr Opin Allergy Clin Immunol 2005: 5: 293-8.
22. Russell S, Monroe K, Losek JD. Anaphylaxis management in the pediatric emergency department: opportunities for improvement. Pediatr Emerg Care 2010: 26: 71-6.

23. Moneret-Vautrin DA, Morisset M, Flabbee J, Beaudouin E, Kanny G. Epidemiology of life-threatening and lethal anaphylaxis: a review. Allergy 2005: 60: 443-51.

24. Sampson HA, Mendelson L, Rosen JP. Fatal and near-fatal anaphylactic reactions to food in children and adolescents. $N$ Engl J Med 1992: 327: 380-4.

25. Brown SG. Clinical features and severity grading of anaphylaxis. $J$ Allergy Clin Immunol 2004: 114: 371-6.

26. Mullins RJ. Anaphylaxis: risk factors for recurrence. Clin Exp Allergy 2003: 33: 1033-40.

27. Simons FE. Anaphylaxis in infants: can recognition and management be improved? $J$ Allergy Clin Immunol 2007: 120: 537-40.

28. Novembre E, Cianferoni A, Bernardini R, et al. Anaphylaxis in children: clinical and allergologic features. Pediatrics 1998: 101: E8.

29. Lane RD, Bolte RG. Pediatric anaphylaxis. Pediatr Emerg Care 2007: 23: 49-56; quiz 57-60.

30. Lee JM, Greenes DS. Biphasic anaphylactic reactions in pediatrics. Pediatrics 2000: 106: 762-6.

31. Pumphrey RS. Lessons for management of anaphylaxis from a study of fatal reactions. Clin Exp Allergy 2000: 30: 1144-50.

32. Bock SA, Munoz-Furlong A, Sampson HA Fatalities due to anaphylactic reactions to foods. J Allergy Clin Immunol 2001: 107: 191-3.

33. Bock SA, Munoz-Furlong A, Sampson HA. Further fatalities caused by anaphylactic reactions to food, 2001-2006. J Allergy Clin Immunol 2007: 119: 1016-8.

34. Pumphrey R. Anaphylaxis: can we tell who is at risk of a fatal reaction? Curr Opin Allergy Clin Immunol 2004: 4: 285-90.

35. Pumphrey RS, Gowland MH. Further fatal allergic reactions to food in the United 
Kingdom, 1999-2006. J Allergy Clin Immunol 2007: 119: 1018-9.

36. Greenberger PA, Rotskoff BD, Lifschultz B. Fatal anaphylaxis: postmortem findings and associated comorbid diseases. Ann Allergy Asthma Immunol 2007: 98: 252-7.

37. Anchor J, Settipane RA. Appropriate use of epinephrine in anaphylaxis. Am J Emerg Med 2004: 22: 488-90.
38. Beno SM, Nadel FM, Alessandrini EA. A survey of emergency department management of acute urticaria in children. Pediatr Emerg Care 2007: 23: 862-8.

39. Webb LM, Lieberman P. Anaphylaxis: a review of 601 cases. Ann Allergy Asthma Immunol 2006: 97: 39-43.

40. Braganza SC, Acworth JP, McKinnon DR, Peake JE, Brown AF. Paediatric emergency department anaphylaxis: different patterns from adults. Arch Dis Child 2006: 91: 159-63.

41. Lieberman P. Biphasic anaphylactic reactions. Ann Allergy Asthma Immunol 2005: 95: 217-26; quiz 226, 258. 